\title{
A New Method for the Measurement of Acute
}

\section{Alterations in Thyroxine Deiodination Rate in Man}

\author{
JoHN T. NICOLOFF \\ From the Department of Medicine, University of Southern California School \\ of Medicine and Los Angeles County/University of Southern California \\ Medical Center, Los Angeles, California 90033
}

\begin{abstract}
A в S T R A C T A newly devised dual labeled iodine isotopic method is described for the detection and quantitation of alterations in thyroxine $\left(T_{4}\right)$ deiodination rate in man. This method employs the principle of a constant ${ }^{120} \mathrm{I}$ infusion to serve as a reference source for the generation of ${ }^{131} \mathrm{I}$ derived from the deiodination of $\mathrm{T}_{4}{ }^{131} \mathrm{I}$. Measurement of these two iodide isotopes are made in serially timed urine collections and are expressed in terms of a ratio value. Using this technique, it was possible to measure accurately the effects of a single dose of 6-propylthiouracil (6-PTU) in producing inhibition of $T$, deiodination in euthyroid subjects. It was also possible to assess the time of onset, duration of action, and degree of inhibition produced by 6-PTU. Employing single doses of 6-PTU, ranging from 100 to $1000 \mathrm{mg}$, there was found to be a $\log$ dose relationship with a degree of inhibition observed in $T_{4}$ deiodination. In control studies $T$, deiodination rate was found to be constant for periods ranging up to $72 \mathrm{hr}$ in normal ambulating subjects. The acute administration of many other agents was employed in an attempt to alter the $T$. deiodination rate. These included diphenylhydantoin, methimazole, triiodothyronine, thyroxine, thyroid stimulating hormone (TSH), adrenocorticotropin (ACTH), hydrocortisone, predinsolone, potassium iodide, epinephrine, and oxytocin. No detectable change in $T_{4}$ deiodination rate was observed with these agents in the dosage ranges employed in this study. The lack of any observable alteration in the $T$. deiodination rate in response to this array of drugs and hormones appears to indicate that the availability of $T$, to intracellular sites of deiodination and possibly action is well modulated to resist abrupt changes.
\end{abstract}

Received for publication 2 June 1969 and in revised form 18 August 1969.

\section{INTRODUCTION}

A number of recent studies have been directed toward the measurement of changes in thyroxine $\left(T_{4}\right)$ disposal rate in man in response to both thyroidal and nonthyroidal disease, as well as to a variety of pharmacological and physiological stimuli (1-10). The close correlation generally observed between $T_{4}$ disposal rate and peripheral hormonal action would appear to underscore the importance of these studies (11-16). The majority of these investigations have relied primarily upon the determination of labeled $T_{4}$ turnover rates in either the plasma or the whole body.

Since $T_{4}$ disposal is the resultant of two rather distinct processes, i.e. (a) degradative deiodination and $(b)$ biliary excretion, it would seem fundamental to the understanding of these previous studies to determine by which of the two routes $T$, disposal was altered. This present investigation has been directed expressly at establishing a technique for the quantitative measurement of alterations in one of these mechanisms for thyroxine disposal, namely $T_{4}$ deiodination rate. Additionally, the proposed method will allow measurement of the rapidity of onset, the duration of action, as well as the magnitude of changes in the $T_{t}$ deiodination rate.

\section{METHODS}

Study subjects. The subjects in this investigation were hospitalized as inpatients at the Clinical Research Center of the Los Angeles County/University of Southern California Medical Center. They displayed no clinical or laboratory evidence of thyroid disease, but they did have incidental diseases such as peptic or gastric ulcer, mild chronic renal disease, and dietary-controlled diabetes mellitus. None of these subjects displayed proteinuria when studied. Patients were encouraged to ambulate freely and to alter as little as possible their normal living pattern during the testing period.

Materials. A pulse tracer dose of $20-30 \mu \mathrm{Ci}$ of $3^{\prime}, 5^{\prime}-$ labeled $\mathrm{T}_{4}{ }^{181} \mathrm{I}$ (Abbott Laboratories, North Chicago, Ill.) 
was administered intravenously 2-4 day before the initiation of a study. This time interval allowed the labeled isotope to approach a state of equilibration with the extrathyroidal $T_{4}$ pools. The specific activity of the administered $T_{4}$ isotope was greater than $20 \mu \mathrm{Ci} / \mu \mathrm{g}$ at the time of administration. A constant infusion of $500 \mathrm{ml}$ of an $0.9 \%$ sterile $\mathrm{NaCl}$ solution, containing $10 \mu \mathrm{Ci}$ of carrier-free sodium- ${ }^{125} \mathrm{I}$ was then used to initiate the study. The infusion was administered through an indwelling polyethylene catheter or a pediatric scalp vein needle into a peripheral arm vein at a rate of approximately $10 \mathrm{ml} / \mathrm{hr}$. Usually a loading dose of ${ }^{125} \mathrm{I}$, equal to the amount of isotope to be infused over an $8 \mathrm{hr}$ period, was given initially to hasten peripheral isotopic equilibration. The infusion system employed was a portable roller type pump (Holter Pump, R.D. 044, Holter Company, Bridgeport, $\mathrm{Pa}$.).

Testing procedures. The collection of a series of separate timed urine samples was then started and continued for the duration of the $36 \mathrm{hr}$ study period. An increase in oral consumption of water was encouraged so that urine samples could be obtained at approximately hourly intervals. Each sample was voided into a $150 \mathrm{ml}$ glass urine specimen bottle, which contained $3 \mathrm{cc}$ of IRA 400 anion exchange resin chloride cycle, 20-50 mesh (Mallinckrodt Chemical Co., St. Louis, Mo.). The resin was incubated with the urine for a $24 \mathrm{hr}$ period at room temperature to allow the majority of the labeled I to be concentrated in the resin granules. Urine samples were then decanted. Residual resin was transferred to a glass counting tube. Variations in the volume of resin for each sample were equalized so as to

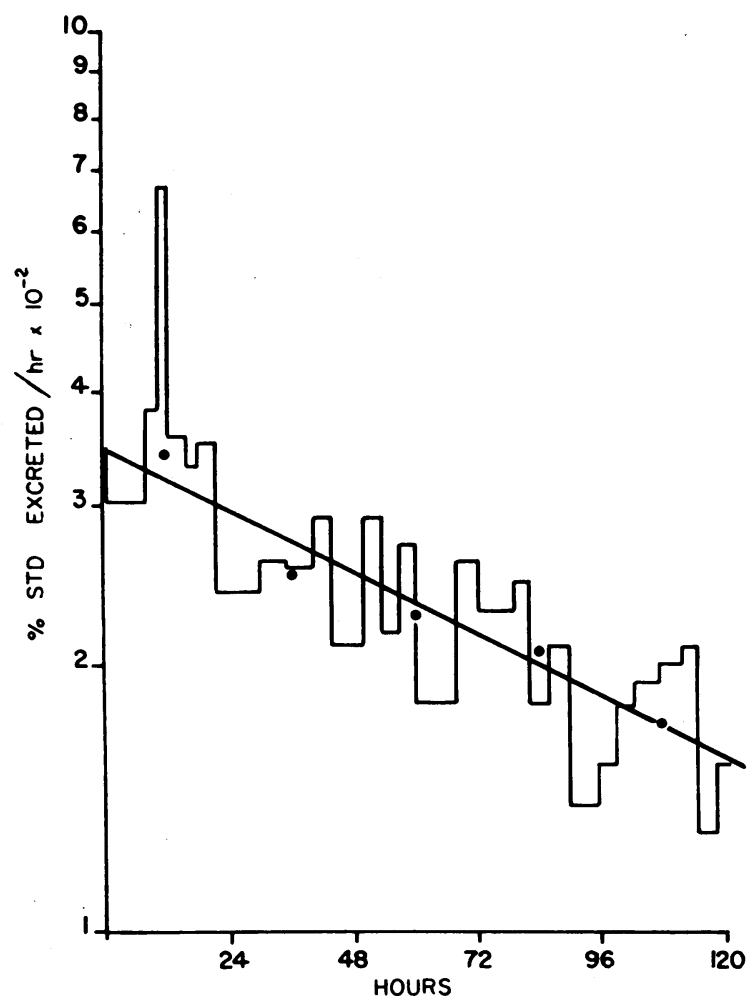

Figure 1 The hourly ${ }^{131}$ I excretion rate after a pulse tracer dose of thyroxine- ${ }^{131} \mathrm{I}$. Closed circles represent the mean urinary excretion for each $24 \mathrm{hr}$ period. obtain uniform counting geometry. All test samples for a given study were counted in an automatic well-type scintillation counter employing a dual channel spectrophotometer (Baird-Atomic Inc., Cambridge, Mass.). No routine attempt was made to quantitate the recovery of labeled I from the urine, but recovery was greater than $50 \%$ when measured. The net counts for each isotope were expressed as a ratio of the ${ }^{131} \mathrm{I}$ (derived from $\mathrm{T}_{4}$ deiodination) over ${ }^{125} \mathrm{I}$ (derived from the constant infusion pump). In some studies the serum $T_{4^{-}}{ }^{131} \mathrm{I}$ activities were obtained during the test period and the disappearance slope was plotted for comparison with the urinary ${ }^{131} \mathrm{I}:{ }^{125} \mathrm{I}$ ratio values. All results were plotted on semilogarithmic coordinates against the time when each sample was collected.

\section{RESULTS}

Urinary sampling was employed in this study for the purpose of measuring alterations in labeled $\mathrm{T}_{4}$ rate. Advantage was taken of the observation (17) that $T_{4}$ was virtually excluded from the urine in the absence of proteinuria as a result of its avid binding to the serum $T_{4}$ binding proteins. In contrast to $T_{4}$, $I$ which is produced from $T_{4}$ deiodination was rapidly cleared into the urine. This renal partitioning of substrate $\left(T_{4}\right)$ and product (I) thus became a useful tool for assessing alterations in $T_{4}$ deiodination.

During the preliminary phases of this investigation, an attempt was made to measure $T_{4}$ deiodination rates without employing a dual tracer system. 3 days after the administration of a pulse tracer dose of $\mathrm{T}_{4}{ }^{131} \mathrm{I}$, quantitative collections of serial-timed urines were performed. Thyroid uptake of labeled I was blocked during the study period by 10 drops of saturated solution of potassium I administered twice daily. Calculation of the excretion rate of the ${ }^{131} \mathrm{I}$ in each sample, in terms of the percentage of the injected dose per hour, was then assessed. The results are plotted in Fig. 1. In spite of the large variations in the hourly excretion rate of ${ }^{131} \mathrm{I}$, the mean daily values were observed to fall along a linear declining exponential slope which paralleled the labeled $\mathrm{T}_{4}$ activity in the plasma from which it was derived. Unfortunately, there was no way, employing the single isotope approach, to distinguish whether the daily fluctuations resulted from alterations in renal iodide clearance and/or $T_{\star}$ deiodination rate.

The introduction of a constant infusion of ${ }^{125} \mathrm{I}$ as a reference source for the I release from the deiodination of $\mathrm{T}_{4^{-}}{ }^{131} \mathrm{I}$ served to resolve the problem of variation in renal $I$ clearance. After equilibration of the $T_{4}$ and $I$ tracers in their respective extrathyroidal pools, any variation in the rate of $T_{4}$ deiodination was then reflected as a change in the ratio of the two I isotopes as they passed into each urine sample. Alterations in the rate of I clearance, either by the thyroid, kidney, or by and other route, would be excluded using this approach. In addition, quantitative recoveries of the $I$ isotopes were unnecessary since the counts were expressed in 
terms of a ratio of $T_{4}$ derived $I$ counts to constant infusion derived I counts for a given timed urine sample.

Spontaneous variations in thyroxine deiodination. Six control studies were performed for periods varying between 24 and $72 \mathrm{hr}$ in an attempt to ascertain whether

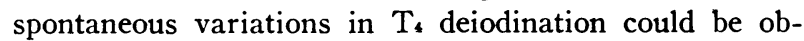
served. No discernible alteration in the linearity of the urinary ratio slopes was found. Similar findings were obtained during the 12-36 $\mathrm{hr}$ interval incorporated as a control period in the studies where testing agents were employed.

The influence of 6-propylthiouracil (6-PTU) on thyroxine deiodination. 16 studies were performed on 11 subjects designed to explore the effects of a single orally-administered dose of 6-PTU on $\mathrm{T}_{4}$ deiodination. Fig. 2 portrays the results of one such study. During the initial $8 \mathrm{hr}$ of this study, a precipitous drop in the urinary ratio slope was observed. This drop was a reflection of the infused ${ }^{125} \mathrm{I}$ approaching equilibration with the extrathyroidal I pool. The prolonged equilibration period resulted, in this instance, because no loading dose of ${ }^{125} \mathrm{I}$ was employed. The $8-27 \mathrm{hr}$ interval served as a control period for the evaluation of spontaneous variations in the $T_{4}$ deiodination rate. Clearly, none were observed within the limits of sensitivity of the method. After 6-PTU was administered orally, a prompt decline in the ${ }^{131} \mathrm{I}:{ }^{125} \mathrm{I}$ ratio slope was observed. This downward deflection represented a decrease in the generation of ${ }^{1: 11} \mathrm{I}$ resulting from $T_{*}$ deiodination. After a $4 \mathrm{hr}$ period, a reversal of the slope was seen. By $8 \mathrm{hr}$, after this single dose of 6-PTU, the ratio slope was observed to fall on the extrapolated control slope values. At $40 \mathrm{hr}$, the ${ }^{125} \mathrm{I}$ constant infusion was discontinued and the change in ratio values was followed for several hours in an effort to establish an I disappearance slope.

In the remaining 20 studies employing single 6-PTU doses, similar results were observed. The dosage range employed varied between 100 and $1000 \mathrm{mg}$ of 6-PTU. After 6-PTU administration, the extrapolated ${ }^{131} \mathrm{I}:{ }^{125} \mathrm{I}$ slope was always reestablished. This indicated that although substantial inhibition of deiodination had occurred there was no net alteration in the total $T_{4}$ disposal rate after 6-PTU administration. This was confirmed when plasma $T_{\mathbf{t}^{-}}{ }^{131} \mathrm{I}$ activity was concomitantly determined as is shown in Fig. 2.

The consistent manner of 6-PTU action, in abruptly depressing the ${ }^{131} \mathrm{I}:{ }^{125} \mathrm{I}$ ratio slope, allowed analysis of the degree of this inhibition for any given administered dose. The method of analysis is based on the concept that if labeled $T_{4}$ deiodination rate was inhibited completely the expected change in the slope of ${ }^{191} \mathrm{I}:{ }^{125} \mathrm{I}$ ratio would be dependent upon the fractional rate of ${ }^{231} \mathrm{I}$ clearance. This value $(k)$ can be determined as follows : if $k_{1}=$ the fractional rate of $T_{4}$ disposal, $k_{3}=$ the rising slope observed after ${ }^{125} \mathrm{I}$ infusion is terminated, and $\mathrm{k}_{3}=$ the declining slope observed after 6-PTU administration, then it follows that $\mathrm{k}$ may be calculated as:

$$
\mathrm{k}=\mathrm{k}_{\mathrm{l}}-\mathrm{k}_{3}
$$

Or in terms of half-life measurements this may be expressed as :

$$
k=\frac{0.693}{t_{1 / 2}}-\frac{0.693}{t_{2 / 1}}
$$

where $t_{1 / 2}=$ half-life of $T_{4}$ disposal and $t_{2 / 1}=$ time required for doubling of the ratio value above the projected control ratio.

After 6-PTU administration, the observed change in slope may expressed as:

$$
\mathrm{k}_{0}=\mathrm{k}_{2}-\mathrm{k}_{1}
$$

Or in terms of half-life measurements, this may be expressed as :

$$
\mathrm{k}_{0}=\frac{0.693}{\mathrm{t}_{1 / 2}^{\prime}}-\frac{0.693}{\mathrm{t}_{1 / 2}}
$$

where $t^{\prime}{ }_{1 / 2}=$ half-life of the decline in the ratio from the. projected control ratio.

The percentage inhibition was then calculated as:

$$
\text { per cent } 6 \text {-PTU inhibition }=\mathrm{k}_{0} / \mathrm{k}_{1} \times 100
$$

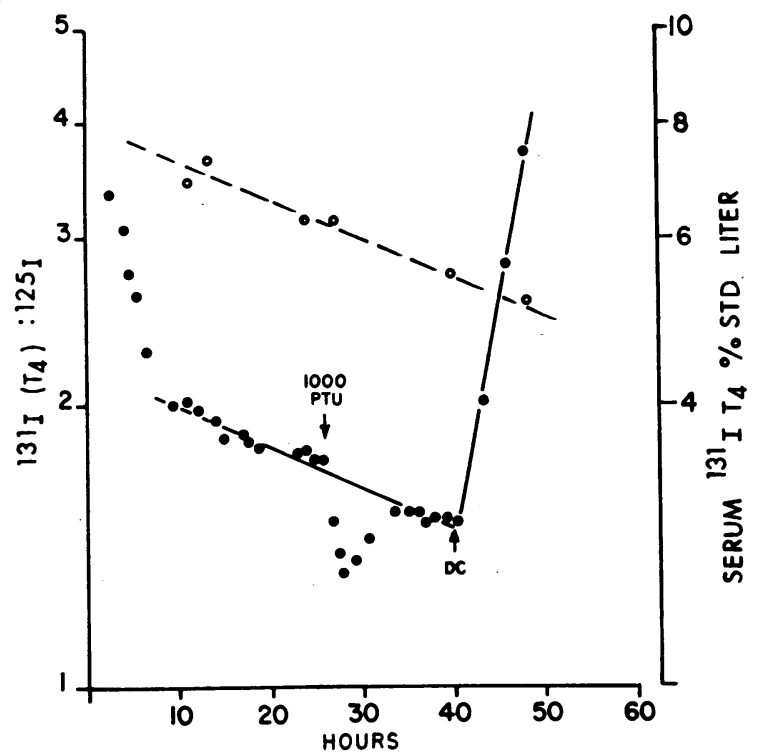

FIGURE 2 The alteration of thyroxine- ${ }^{131} \mathrm{I}$ deiodination rate after a single oral dose of 6-propylthiouracil. The rapid fall of the ${ }^{181} \mathrm{I}:{ }^{125} \mathrm{I}$ slope during the first $8 \mathrm{hr}$ of the study is a result of the ${ }^{125} \mathrm{I}$ achieving equilibration with the extrathyroidal iodide pool. The symbol DC indicates when the ${ }^{125} \mathrm{I}$ infusion was discontinued. The closed circles represent urinary ${ }^{181} \mathrm{I}:{ }^{125} \mathrm{I}$ ratio values and the open circles serum $\mathrm{T}_{4^{-1}}{ }^{131} \mathrm{I}$ activity. 


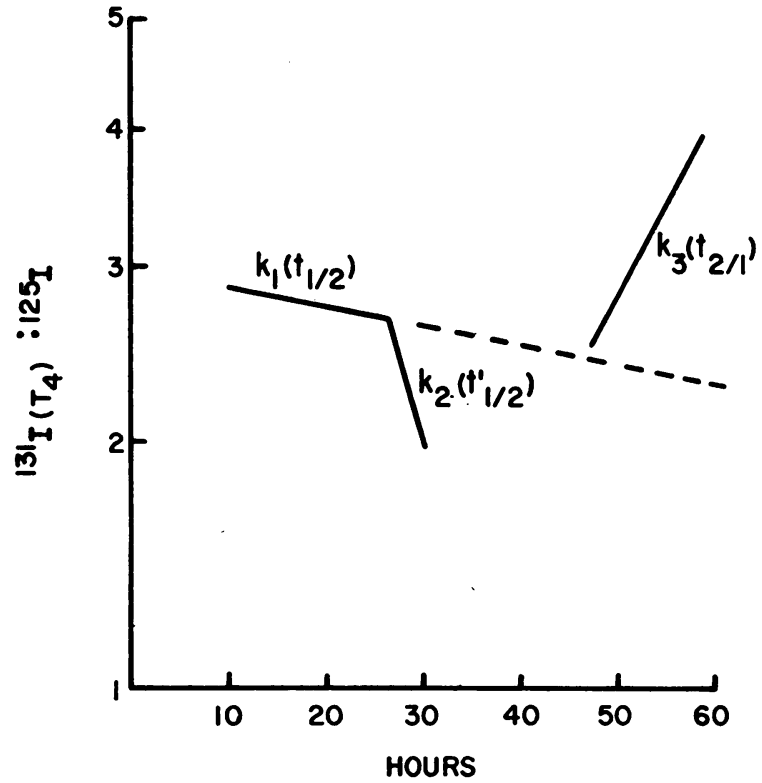

FIgURE 3 This is a diagramatic representation of the measurements employed for the slope analysis of the data obtained in this study. The symbol $k_{1}$ represents the extrapolation of this slope. The symbol $\mathrm{k}_{2}$ represents the slope after 6-PTU administration and $k_{3}$ the slope after discontinuing the ${ }^{125} \mathrm{I}$ infusion.

The $t_{1}, t^{\prime} t_{1}$, and $t_{2 / 1}$ values were directly determined from the plotted data for each study. This is diagramatically illustrated in Fig. 3.

The results of this form of analysis, on the subjects having received 6-PTU, are portrayed in Fig. 4. There appears to be a log dose inhibitory response of 6-PTU on $T_{4}$ deiodination rate over the dosage range employed.

When larger doses of 6-PTU were given, a somewhat greater duration of inhibition was noted but this never exceeded $6 \mathrm{hr}$. In contrast, when dosages were administered at hourly intervals over a $10 \mathrm{hr}$ period, a much longer period of inhibition of deiodination was produced (Fig. 5).

Many drugs and hormonal substances were screened in a manner similar to that which was employed in the 6-PTU studies. The results are summarized in Table I. Methimazole (Tapazole), which has a similar action to 6-PTU in blocking iodine organification in the thyroid, had no effect on the peripheral deiodination of $\mathrm{T}_{4}$. Diphenylhydantoin (Dilantin) likewise was without any effect even when administered at five times the daily therapeutic dose. The administration of triiodothyronine, thyroxine, iodides, thyrotropin, corticotropin, hydrocortisone, prednisolone, epinephrine, and oxytocin in varying dosage levels also caused no detectable acute alteration in thyroxine deiodination rate.

\section{DISCUSSION}

The method described in this investigation was designed for the accurate measurement of any factor which might acutely affect the rate of $T_{4}$ deiodination. The method did not require the determination of either $I$ or $T_{4}$ distribution spaces. Although $\mathrm{T}_{4}$ deiodination half-times could not be calculated, quantitation of the degree and duration of inhibition or acceleration in $\mathrm{T}_{4}$ deiodination was measurable. The major weakness of the method was that it required a constant infusion pump system and a minimum infusion period of $36 \mathrm{hr}$. Although the infusion pump was portable, it did limit the range of application and duration of a study. In addition, it was also possible that alterations in $\mathrm{T}_{4}$ deiodination rates, which might have occurred gradually over a time span of several days or weeks, could not be detected.

Anbar, Guttmann, Rodan, and Stein (15) have previously described a similar dual-labeled iodine method for the estimation of $T$, deiodination rate or half-life. In contrast to the present study, these investigators utilized a pulse-labeling technique for both $\mathrm{T}_{4}$ and $\mathrm{I}$ tracers. Levy, Marshall, and Sheehan (16) have seriously questioned the validity of the methodology employed by Anbar, Guttmann, Rodan, and Stein (15). Their principal objection concerned the assumptions that the $T_{4}$ and I tracers had similar extrathyroidal distribution spaces and that the I tracer had achieved an adequate state of equilibration when the studies were performed. Correction for the differences in I and $T_{4}$ pool sizes can be employed, as was done by Levy, Marshall, and Sheehan (16), but this adds greatly to the complexity of the study. In addition, the use of a single pulse I tracer may be associated with further inaccuracies. In the first few hours postinjection, there may be nonlinearity of the I disappearance due to compartmental mixing. After $12 \mathrm{hr}$, the plasma I slope again appears to become nonlinear suggesting a possible slowly equilibrating I pool

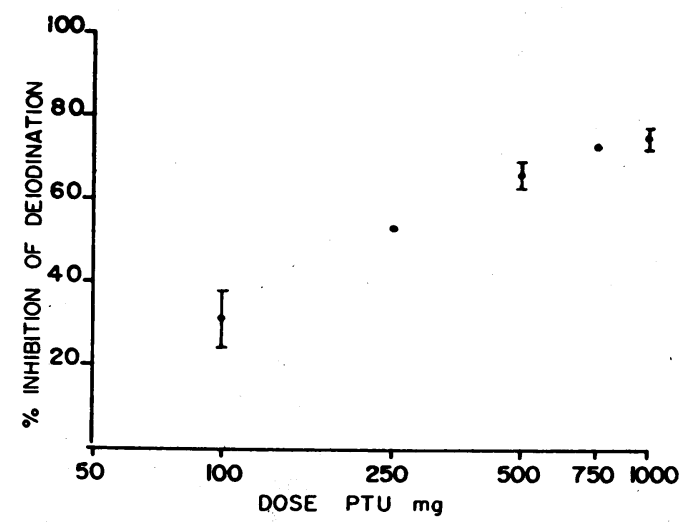

FIgURe 4 The dose response curve of the inhibitory action of 6-propylthiouracil on thyroxine-131 I deiodination. Vertical bars incorporate 1 SEM value. 
or recycling from the alimentary tract (16). These problems, attendant with pulse-labeling, would appear to seriously jeopardize the usefulness of the technique described by Anbar, Guttman, Rodan, and Stein (15) and later modified by Levy, Marshall, and Sheehan (16).

This study clearly indicated that 6-PTU uniformly inhibited $T_{4}$ deiodination $(6,7)$. Although 6-PTU will cause an abrupt inhibition in $T_{4}$ deiodination, other routes of $T$, disposal appeared to be reciprocally augmented such that total serum $T_{4}$ disposal rate was essentially unchanged. Apparently a marked augmentation in stool losses of labeled $T_{4}$, as previously pointed out by Hershman (6), virtually compensated for the decrease in urinary excretion. The observation that the extrapolated control ${ }^{181} \mathrm{I}:{ }^{228} \mathrm{I}$ slope was reestablished after the dissipation of the 6-PTU drug effect, as illustrated in Fig. 2 lends some support to this conclusion. If this reciprocal relationship between deiodination and biliary excretion had not occurred, there would have been a net conservation of labeled $\mathrm{T}_{4}$ when 6-PTU was administered. This effect would have resulted, in turn, in a flattening out of the plasma disposal slope during the 6-PTU administration and an elevation of the urinary ratio slope above the extrapolated control slope after the withdrawal from the 6-PTU drug effect.

The major site of action of 6-PTU on the peripheral tissue alteration of $T$, deiodination appears most likely to be the liver, although similar effects have been observed in kidney slices (18). Since the liver contains deiodinating as well as conjugating enzyme systems for thyroxine, one may speculate that if the hepatic cells were unable to deiodinate $T$, the alternative route of

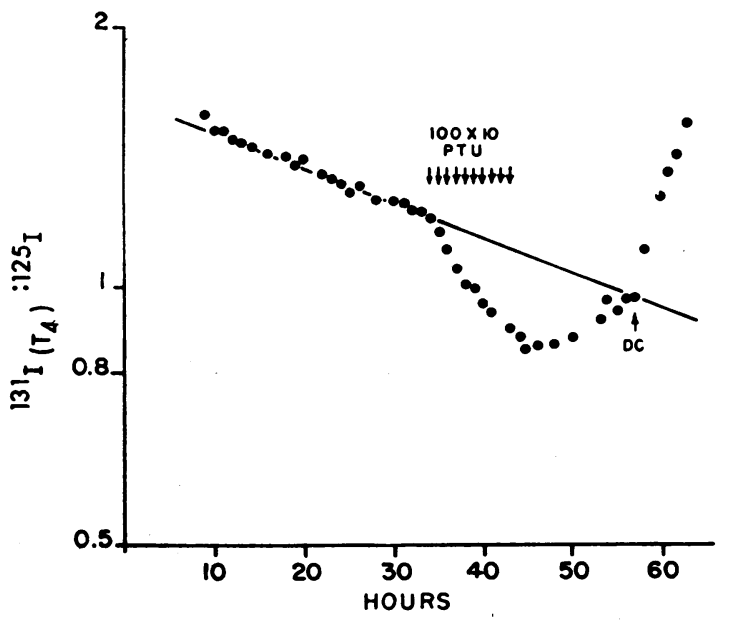

FIGURE 5 The prolongation of inhibition of thyroxine- ${ }^{131} \mathrm{I}$ deiodination by the administration of frequent doses of 6-propylthiouracil. The symbol DC indicates when the ${ }^{125} \mathrm{I}$ infusion was discontinued.
TABLE I

Drugs and Hormones Which Have Failed to Cause an Acute Change in Thyroxine Deiodination Rates

\begin{tabular}{lllc}
\hline \multicolumn{1}{c}{ Agent } & \multicolumn{1}{c}{ Route } & \multicolumn{1}{c}{$\begin{array}{c}\text { Dosage } \\
\text { range }\end{array}$} & $\begin{array}{c}\text { No. of } \\
\text { subjects } \\
\text { treated }\end{array}$ \\
\hline 1. Diphenylhydantoin & $\begin{array}{l}\text { Oral } \\
\text { Intravenous }\end{array}$ & $\begin{array}{l}500-2000 \mathrm{mg} \\
250-500 \mathrm{mg}\end{array}$ & 4 \\
2. Methimazole & Oral & $100 \mathrm{mg}$ & 2 \\
3. Triiodothyronine & Oral & $100-200 \mathrm{mg}$ & 6 \\
4. Thyroxine & Oral & $2.0 \mathrm{mg}$ & 2 \\
5. Thyrotropin & Intramuscular & $10 \mathrm{U}$ & 2 \\
6. Corticotrophin gel & Intramuscular & $40-80 \mathrm{U}$ & 2 \\
7. Hydrocortisone & Intravenous & $200 \mathrm{mg}$ & 2 \\
8. Prednisolone & Oral & $60 \mathrm{mg}$ & 4 \\
9. Potassium iodide & Oral & $200 \mathrm{mg}$ & 4 \\
10. Epinephrine & Subcutaneous & $0.3 \mathrm{mg}$ & 2 \\
& Intravenous & $20-50 \mathrm{\mu g} / \mathrm{min}$ & 2 \\
11. Oxytocin & Intramuscular & $10 \mathrm{U}$ & 4 \\
\hline
\end{tabular}

glucuronide conjugation and biliary excretion would then be utilized (19). The demonstration that 6-PTU and other thiourea drugs alter liver size, oxygen uptake. and protein metabolism $(20,21)$ would lend credence to this speculation.

Methimazole, a drug similar to 6-PTU in its antithyroid action, was not observed to inhibit peripheral $\mathrm{T}_{4}$ deiodination. These differences in inhibitory action of 6-PTU and methimazole have been observed previously by many investigators in vivo and in vitro in laboratory animal experimentation (19). It appears that the antithyroid activity and the inhibitory action on $\mathrm{T}$ 4 deiodination of a variety of antithyroid drugs do not closely correlate (22). This observation may indicate that these drugs act in some fundamentally different way in inhibiting perioxidase enzyme systems involved in $T_{4}$ formation and deiodination. Another possibility is that the penetration of methimazole into an extrathyroidal site of action was not comparable to that found in the thyroid gland itself.

Although it was of great interest that 6-PTU did inhibit $T_{4}$ deiodination, it was also apparent that in normal ambulating subjects, as well as in patients receiving a number of pharmacological and hormonal substances, $T_{4}$ deiodination rate was remarkably constant (Table I). This constancy may, in part, be a reflection of the modulating effect of the large pool of exthrathyroidal $T$, bound to the specific circulating thyroxine-binding proteins.

It was surprising that such an agent as diphenylhydantoin did not alter $T_{4}$ deiodination rate. Previous concepts of the action of diphenylhydantoin suggested that it should have displaced $T_{4}$ from the serum $T$. 
binding globulin and made it more available to intracellular deiodinating sites $(23-26)$. This increased availability of $T_{*}$ to intracellular sites should have then resulted in a significant increase in the rate of $T_{4}$ deiodination. Indeed, Oppenheimer, Bernstein, and Hasen have demonstrated that such an intracellular compartmental shift does occur in $\mathrm{T}_{4}$ distribution in man during the intravenous infusion of $150 \mathrm{mg}$ of diphenylhydantoin (27). Yet, at doses of $500 \mathrm{mg}$ intravenously or $2000 \mathrm{mg}$ orally, diphenylhydantoin could not be demonstrated to result in any detectable acute alteration in $T_{4}$ deiodination rate in our studies. Resolution of these apparently disparate findings may be evident from the work of Mendoza, Flock, Owen, and Paris in the rat (28). They demonstrated, both in the whole animal and in isolated liver infusion studies, that diphenylhydantoin does not acutely result in alterations in $T_{4}$ deiodination rate, but when a pretreatment period of 3-13 day was employed, marked alterations in $T_{4}$ metabolism could be observed. Recently, Chin and Schussler (29) have observed a significant lowering of "free" thyroxine values in some patients receiving diphenylhyclantoin therapy which inferred a possible alteration in the feedback regulatory mechanisms for $T_{t}$ secretion. It appears that the mode of action of diphenylhydantoin on thyroxine metabolism may be considerably more complex than has been previously realized.

Special note should possibly be made of the negative responses observed with epinephrine and glucocorticoid administration. In spite of previous conflicting data obtained from animal experimentation, recent work by Hays and Solomon has revealed little effect of chronic administration of epinephrine on peripheral $\mathrm{T}_{4}$ deiodination rate in man $(30)$. The present understanding of the action of glucocorticoids on thyroid hormone metabolism in experimental animals is also unclear (19), but it appears that glucocorticoids do not significantly alter $T_{4}$ disposal rate in man (31).

It should be emphasized that the negative responses to these agents should be considered in light of the limitation of the method to detect only acute alterations in $T_{4}$ deiodination. Thus, it would not be possible to reflect changes which might have occurred over a longer time span. Moreover, the dosages of the agents used in this study may not have been adequate to elicit a positive response, although a broad dosage range of each agent was employed in an effort to meet this possibility.

There have been a number of investigations relating to serum "free" $T_{4}$ as a major determinant of hormonal action (32-38). Inherent in all of these studies is the concept that the "free" $T_{4}$ measurement determined in vitro directly relates to the concentration of $T_{4}$ at a hypothetical intracellular site of action. Recently, how- ever, such a correlation has been questioned by Oppenheimer (39). Although a variety of phenomena and agents are associated with changes in extracellular "free" $T_{4}$ levels, there has been no way to determine whether these alterations result in a change in the amount of intracellular $T_{*}$ available for hormonal action. It is anticipated that this presently described method for measuring changes in $T_{4}$ deiodination will allow some insight into this problem by serving as an index for the intracellular availability of $T_{4}$ to hormonal sites of action.

\section{ACKNOWLEDGMENTS}

I wish to gratefully acknowledge the technical assistance of Mr. Dwight W. Warren and the mathematical analysis assistance of Mr. Hojat Rostami.

This work was supported in part by grants from the National Institutes of Health (USPH Service Research Grant AM 11727 and USPH Service General Clinical Research Center Grant RR-43).

\section{REFERENCES}

1. Sterling, K., and R. B. Chodos. 1956. Radiothyroxine turnover studies in myxedema, thyrotoxicosis, and hypermetabolism without endocrine disease. J. Clin. Invest. $35: 806$.

2. Ingbar, S. H., and N. Freinkel. 1958. Studies of thyroid function and the peripheral metabolism of $\mathrm{I}^{131}$-labeled thyroxine in patients with treated Graves' disease. J. Clin. Invest. $37: 1603$.

3. Nicoloff, J. T., and J. T. Dowling. 1968. Studies of peripheral thyroxine distribution in thyrotoxicosis and hypothyroidism. J. Clin. Invest. 47: 2000.

4. Ingbar, S. H., and N. Freinkel. 1960. Regulation of peripheral metabolism of the thyroid hormones. Recent Progr. Hormone Res. 16: 353.

5. Ingbar, S. H. 1960. Clinical and physiological implications of thyroxine turnover in man. Clin. Endocrinol. 1: 91.

6. Hershman, J. M. 1964. Effect of 5-and 6-propylthiouracil on the metabolism of $\mathrm{L}$-thyroxine in man. J. Clin. Endocrinol. Metab. 24: 173.

7. Furth, E. D., K. Rives, and D. V. Becker. 1966. Nonthyroidal action of propylthiouracil in euthyroid, hypothyroid, and hyperthyroid man. J. Clin. Endocrinol. Mctab. 26: 239.

8. Gregerman, R. I., and N. Solomon. 1967. Acceleration of thyroxine and triiodothyronine turnover during bacterial pulmonary infections and fever: implications for functional state of the thyroid during stress and in senescence. J. Clin. Endocrinol. Metab. 27: 93.

9. Bernstein, G., J. Hasen, and J. H. Oppenheimer. 1967. Turnover of ${ }^{131}$ I-thyroxine in patients subjected to surgical trauma. J. Clin. Endocrinol. Metab. 27: 741.

10. Irvine, C. H. G. 1968. Effect of exercise on thyroxine degradation in athletes and non-athletes. J. Clin. Endocrinol. Metab. 28: 942.

11. Galton, V. A., and S. H. Ingbar. 1961. The mechanism of protein iodination during the metabolism of thyroid hormones by peripheral tissues. Endocrinology. 69: 30 .

12. Escobar del Rey, F., and G. Morreale de Escobar. 1961. The effect of propylthiouracil, methylthiouracil and thio- 
uracil on the peripheral metabolism of L-thyroxine in thyroidectomized, L-thyroxine maintained rats. Endocrinology. $69: 456$.

13. Galton, V. A., and S. H. Ingbar. 1962. A photoactivated flavin-induced degradation of thyroxine and related phenols. Endocrinology. 70: 210.

14. Escobar del Rey, F., G. Morreale de Escobar, M. D. Garcia Garcia, and J. Mouriz Garcia. 1962. Increased secretion of thyrotrophic hormone in rats with depressed peripheral deiodination of thyroid hormone and a normal or high plasma PBI. Endocrinology. 71: 859.

15. Anbar, M., S. Guttmann, G. Rodan, and J. A. Stein. 1965. The determination of the rate of deiodination of thyroxine in human subjects. J. Clin. Invest. 44: 1986.

16. Levy, R. P., J. S. Marshall, and M. G. Sheahan. 1968. Theoretical and practical considerations of thyroxine deiodination rates in man. J. Clin. Endocrinol. Metab. 28: 633 .

17. Stanbury, J. B. 1960 . Deiodination of the iodinated amino acids. Ann. N. Y. Acad. Sci. 86: 417.

18. Braverman, L. E., and S. H. Ingbar. 1962. Effects of propylthiouracil and thiouracil on the metabolism of thyroxine and several of its derivatives by rat kidney slices in vitro. Endocrinology. 71: 701.

19. Rall, J. E., J. Robbins, and C. G. Lewallen. 1964. The thyroid. In The Hormones: Physiology, Chemistry and Applications. G. Pincus, K. V. Thinmann, and E. B. Astwood, editors. Academic Press, Inc., New York. 5: 159.

20. Borell, U., and $\mathrm{Hj}$. Holmgren. 1948. The effect of methylthiouracil on the oxygen consumption of the thyroid, liver and kidney. Endocrinology. 42: 427.

21. Yatvin, M. B., R. W. Wannemacher, Jr., and W. L. Banks, Jr. 1964. Effects of thiouracil and of thyroidectomy on liver protein metabolism. Endocrinology. 74: 878.

22. Hirshman, J. M., and L. Van Middlesworth. 1962. Effect of antithyroid compounds on the deiodination of thyroxine in the rat. Endocrinology. 71: 94.

23. Wolff, J., M. E. Standaert, and J. E. Rall. 1961. Thyroxine displacement from serum proteins and depression of serum protein-bound iodine by certain drugs. J. Clin. Invest. 40: 1373.

24. Oppenheimer, J. H., and R. R. Tavernetti. 1962. Studies on the thyroxine-diphenylhydantoin interaction: effect of $5,5^{\prime}$-diphenylhydantoin on the displacement of L-thyroxine from thyroxine-binding globulin (TBG). Endocrinology. 71: 496

25. Oppenheimer, J. H., and R. R. Tavernetti. 1962. Displacement of thyroxine from human thyroxine-binding globulin by analogues of hydantoin: steric aspects of thyroxine-binding site. J. Clin. Invest. 41: 2213.
26. Oppenheimer, J. H., L. V. Fisher, K. M. Nelson, and J. W. Jailer. 1961. Depression of the serum protein-bound iodine level by diphenylhydantoin. J. Clin. Endocrinol. Metab. 21: 252 .

27. Oppenheimer, J. H., G. Bernstein, and J. Hasen. 1967. Estimation of rapidly exchangeable cellular thyroxine from the plasma disappearance curves of simultaneously administered thyroxine- ${ }^{131} \mathrm{I}$ and albumin ${ }^{125} \mathrm{I}$. J. Clin. Inr'est. 46: 762.

28. Mendoza, D. M., E. V. Flock, C. A. Owen, Jr., and J. Paris. 1966. Effect of 5,5'-diphenylhydantoin on the metabolism of L-thyroxine- ${ }^{131} \mathrm{I}$ in the rat. Endocrinology. 79: 106.

29. Chin, W., and G. C. Schussler. 1968. Decreased serum free thyroxine concentration in patients treated with diphenylhydantoin. J. Clin. Endocrinol. Metab. 28: 181.

30. Hays, M. T., and D. H. Solomon. 1969. Effect of epinephrine on the peripheral metabolism of thyroxine. J. Clin. Invest. 48: 1114.

31. Ingbar, S. H., and N. Freinkel. 1956. ACTH, cortisone and the metabolism of iodine. Metabolism. 5: 652 .

32. Oppenheimer, J. H., and M. I. Surks. 1964. Determination of free thyroxine in human serum: a theoretical and experimental analysis. J. Clin. Endocrinol. Metab. 24: 785.

33. Surks, M. I., and J. H. Oppenheimer. 1964. Postoperative changes in the concentration of thyroxine-binding prealbumin and serum free thyroxine. J. Clin. Endocrinol. Metab. 24: 794.

34. Ingbar, S. H., L. E. Braverman, N. A. Dawber, and G. Y. Lee. 1965. A new method for measuring the free thyroxine hormone in human serum and an analysis of the factors that influence its concentration. J. Clin. Invest. 44: 1679.

35. Sterling, K., and M. A. Brenner. 1966. Free thyroxine in human serum: simplified measurement with the aid of magnesium precipitation. J. Clin. Invest. 45: 153.

36. Bernstein, G., and J. H. Oppenheimer. 1966. Factors influencing the concentration of free and total thyroxine in patients with nonthyroidal disease. J. Clin. Endocrinol. Metab. 26: 195.

37. Hollander, D., J. C. Meek, and R. T. Manning. 1967. Determination of free thyroxine in serum of patients with cirrhosis of liver. N. Engl. J. Med. 276: 900.

38. Arango, G., W. E. Mayberry, T. J. Hockert, and L. R. Elveback. 1968. Total and free human serum thyroxine in normal and abnormal thyroid states. Mayo Clin. Proc. 43: 503 .

39. Oppenheimer, J. H. 1968. Role of plasma proteins in the binding, distribution and metabolism of thyroid hormones. N. Engl. J. Med. 278: 1153. 